\begin{tabular}{|ccc|}
\hline & ANNALES INSTITUTI SLAVICI \\
& UnIVERSITATIS DEBRECENIENSIS & \\
SLAVICA XLVII & 2018 & DEBRECEN \\
\hline
\end{tabular}

\author{
Андрей ЧукУРОВ
}

\title{
МЕЖДУ КИБОРГОМ И ЛИЧИНКОЙ: ЗАМКНУТЫЙ КРУГ ЧЕЛОВЕКА ЭПОХИ ПОСТГУМАНИЗМА
}

\section{Between Cyborg and Larva: A Vicious Circle that Human Beings Experience in the Post-humanist Era}

The article reveals the reasons for and specific features of the transition to the posthumanist era. The author of the study reviews the criticism of classical humanism and analyzes the relationship between the concepts of "trans-humanism" and "post-humanism." In a situation in which a permanent identity is impossible and people move to a "current" "unstable" identity, the Imaginary becomes the main guideline for the self-identification process. Human beings are unable to cope with the challenges of our time and are aware of their own inferiority. That is why they are trying to improve themselves through the available body modifications. However, this process gives them a new panic attack over the potential loss of control over the body. Analyzing these processes, the author turns to the most controversial and specific phenomenon of popular culture - "body horror". This genre reveals the deep layers of consciousness, fears and insecurity of human beings in the post-humanist era.

Keywords: posthumanism, transhumanism, classical humanism, body horror, identity, body modifications

Когда-то Мишель Фуко в своей монографии «Слова и вещи» писал, что рано или поздно человек исчезнет. Философ имел в виду не вид Homo sapiens как таковой, а вполне конкретный тип личность: тот самый, что был создан гуманистами эпохи Возрождения. Когда культура перешагнула границу постмодерна и вступила в эру трансмодерна, в эпоху глобализации и информационного общества именно этот тип человека оказывается обречен на исчезновение. Концепция постгуманизма непосредственно указывает именно на это, подчеркивая, что эволюция Homo sapiens как вида не завершена, и при этом выводит на авансцену культурной жизни феномен постчеловека. Исследователи полагают, что дальнейшее развитие технико-технологичекой составляющей культуры выведет нас на следующую ступень эволюции. Насколько изменится наша физиология? Какие возможности мы обретем, и что при этом потеряем? Уже сейчас мы вполне можем разглядеть контуры ближайшего будущего и понять, куда именно движется современная культура благодаря искусству, которое как лакмусовая бумажка мгновенно реагирует на любые социокультурные трансформации, даже если они еще не попали в фокус внимания науки. Прежде всего отметим, что классический гуманизм возрожденческого 
Между киборгом и личинкой...

типа подвергается жесткой критике уже с середины XX века, что вовсе не случайно, ибо тогда происходит распад колониальной системы, а завершившаяся вторая мировая война обнажила несостоятельность культурных парадигм эпохи модернизма, выросших, вне всяких сомнений, из идеалов Нового времени, а значит - концепции классического гуманизма. Критиковал его Хайдеггер М., указывавший, что классический гуманизм представляет человека, изначально выделяющегося своей субъективностью из бытия [ХАЙДЕГГЕР 2002: 451]. Рено А. в своей работе «Эра индивида. К истории субъективности» порицал гуманизм за неприкрытый индивидуализм [РеНО 2002: 473]. А Левинас Э. искал причины кризиса гуманизма в том, что западноевропейская личность сконцентрирована в силу искаженного антропоцентризма на себе и своей тотальности [ЛЕВИНАС 2004: 319-589].

Как бы там ни было, но классический гуманизм, несмотря на все свои красивые тезисы, создал личность, настолько увлеченную своим величием, что она попросту оказалась неспособна разглядеть интересы Другого. Именно поэтому и возникает необходимость в пересмотре основных постулатов гуманизма, что в свою очередь приводит к возникновению концепции постгуманизма. Постгуманизм заявляет о неотъемлемом праве человека на самосовершенствование всеми доступными технико-технологическими средствами в силу того, что сам человек вовсе не является венцом творения и отличается крайней степенью несовершенства. Последний аспект вносит некоторую путаницу в соотношение понятий «постгуманизм» и «трансгуманизм». Кто-то указывает, что трансгуманизм - это некая историческая ступень развития постгуманизма, иные утверждают, что трансгуманизм - это вообще особый тип гуманизма. С нашей точки зрения - это не то и не другое. Трансгуманизм - это составная часть постгуманизма. Сторонники трансгуманизма, заявляющие о его самостоятельности, наивно полагают, что соединение человека и новых технологий (за счет имплантаций и пр.) способно вывести наш вид на более высокий уровень. Однако, это не более чем проявление слепой веры в технологический прогресс, что мы видели на заре модерна XIX века, выстроенной строго в рамках классического гуманизма. Постгуманизм непосредственно заявляет о том, что это не шаг вперед, а шаг в сторону, не более того. Не существует никаких доказательств того, что человечество будет неуклонно двигаться вперед, через кризисы и падения, но вперед. Органично вплетаясь в информационное пространство глобальной паутины, передавая те или иные функции технологическим новинкам, человек создает собственную реальность, но не овладевает миром, не оказывается в центре мироздания, как то представляет классический гуманизм. Мы просто передаем часть своих естественных, природных функций технологии.

Постгуманизм утверждает, что использование новых технологий хоть и расширяет спектр личностных свобод и приводит к гармонизации и самосовершенствованию за счет медицинского вмешательства, но при этом вовсе не превращает человека в высшее существо. Даже идея обретения бессмертия за счет технологии сама по себе не предполагает сохранение человека в том 
виде, в котором мы его знаем: виртуальная реальность сегодня уже дает это бессмертие - физическое тело может быть мертво, a alter ego социальных сетей продолжает жить. Именно глубинное осознание собственного несовершенства и, одновременно, опасности соединения человека и новых технологий приводит к появлению на свет идеи биоэтики. В 1996 году появляется Конвенция Совета Европы о защите прав и достоинства человека в связи с использованием достижений биологии и медицины - «Конвенции о правах человека и биомедицине». Этот документ первоначально имел другое название - «Конвенция по биоэтике». Один из центральных вопросов как самой Конвенции, так и научных дискуссий в русле биоэтики, заключается в защите человека от возможного несанкционированного научного вмешательства. Иными словами, уже на этом, весьма раннем этапе, проявляется страх перед тем, во что может превратиться человек - а далее мы будем говорить непосредственно именно о страхе.

Сегодня мы становимся свидетелями процесса активного соединения технологии и человека. И это не только ставшие привычными эстетическая хирургия, вживление имплантов или вынужденное хирургическое вмешательство - замена костей на специальные каркасы. Вспомним австралийского профессора и известного художника-акциониста Стеларка. Это человек с 2006 года пытается вырастить ухо у себя в руке. Это не просто «декоративный элемент» или третье ухо для самого Стеларка. Посредством этого дополнения к собственному телу любой желающий может воспринимать звуки по Wi-Fi, которые слышит сам создатель: «Ухо - оно не для меня, у меня уже есть два. Это ухо - прибор удаленного слуха для людей в других местах. Они смогут следить за разговором или слушать концерт, где бы я и они не находились. Через GPS они смогут отслеживать, где ухо находится в данный момент» ${ }^{1}$. Есть и другой, куда более успешный и массовый пример, - более 3 тысяч шведов уже вживили себе в руку микрочипы, которые позволяют заменить пластиковые карты, ключи, и пр. Шведы программируют на этот чип данные об абонементах в спортзал, рабочие пропуска и многое другое. Иными словами, человек совершенствуется всеми доступными благодаря технологии способами и это уже наша реальность.

Однако, это не означает, что человек стремится занять чье-то место и снова вступить в войну с природой - подобные проявления агрессии и самолюбования являются как раз наследием эпохи гуманизма - он просто осознает свое несовершенство и пытается обрести собственное место, не занимая чужого. Центральная идея постгуманизма - это идея гармонизации внутреннего и внешнего, обретения целостности через эклектичную фрагментацию. При этом, стремление к подобного рода гармонизации рука об руку идут со страхом телесных трансформаций. Российский философ В.А. Подорога

1 Третье ухо на руке вырастил себе профессор из Австралии / Звезда. - Режим доступа: https://tvzvezda.ru/news/vstrane_i_mire/content/201508122057-hzgx.htm (10.08.2015), свободный. - Загл. с экрана - Яз. Рус. 
утверждает: «...слишком доступное нам переживание собственного тела, которое неожиданно сталкивается с ему противоположным: вы все-таки находитесь внутри особой телесной машины и не имеете над ней полной власти, и в каждое мгновение можете утратить контроль. Ваше собственное тело (переживаемое как вам принадлежащее) в глубинном истоке существования принадлежит не вам, а скорее внешнему миру» [ПодоРОГА 1995]. Страх утратить контроль над тем, что, казалось бы, принадлежит тебе по праву рождения, постоянно возвращает тело в центр художественного пространства.

Поразительным образом страх перед бодимодифиациями и стремление к гармонии соединяются в главном художественном образе нового, постгуманитстического мира - киборге. Аватар (фильм, 2009), Бегущий по лезвию 2049, Ванильное небо, Видоизмененный углерод, Газонокосильщик, Джонни-мнемоник, Искусственный разум, Крикуны, Люси, Матрица, Мир Дикого запада (телесериал), Области тьмы, Превосходство, Призрак в доспехах (аниме, 1995), Призрак в доспехах (фильм, 2017), Робокоп, Робот по имени Чаппи, Суррогаты, Терминатор: Генезис, Титан, Человек-амфибия (фильм, 1961), Элизиум - рай не на Земле, Киборг 2: Стеклянная тень, Киборг-ниндзя, Киборг-охотник, Ксеногенез, Призрак в доспехах (фильм, 2017), Призрак в доспехах: Синдром одиночки (аниме), Призрак в доспехах: Синдром одиночки 2nd GIG (аниме) - это лишь минимальный перечень фильмов, сериалов и аниме, где центральной темой оказывается расширение возможностей человека за счет биологических и технический новаций. Подобные новации пугают и притягивают, а главное - становятся ориентирами для науки и медицины, а многое, из того что представлено в этих фильмах, сегодня уже стало частью реальности. Необходимо помнить, что в эпоху постгуманизма в ходе социализации и самоидентификации у человека больше нет строгих и обязательных ориентиров - он более не соотносит себя ни с родителями, ни с профессиональной или социальной группой. Мы говорим о «плавающей идентичности», когда главную роль в процессе самоидентификации играет Воображаемое.

Не случайно манифест киборга Донны Хароуэй не утрачивает актуальности, а наоборот, получает новые прочтения. «Киборг - создание постгендерного мира, он ничего общего не имеет с бисексуальностью, доэдиповым симбиозом, неотчужденным трудом или прочими соблазнами органической целостности, достигаемой окончательным усвоением всех сил всех частей в некое высшее единство. В какомто смысле у киборга нет истории происхождения в западном понимании; „последняя“ ирония, поскольку киборг - это также чудовищный апокалиптический телос разогнанных западных овладений абстрактной индивидуации, конечная самость, оторванная, наконец, от всякой зависимости, человек в космическом пространстве» [ХАРАУЭЙ 2017: 128]. Автор утверждает, что киборг и есть идеальное соединение материальной реальности и воображения.

Несмотря на широко представленный в популярной культуре и до некоторой степени обнадеживающий образ киборга, именно страх оказывается художественно-эмоциональной доминантой художественного творчества. При этом непосредственно сам ужас телесных трансформаций открыла Мери 
Шелли в своем знаменитом романе 1818 года, многократно экранизированном и интерпретированном - «Франкенштейн, или Современный Прометей». К образу Виктора Франкенштейна и его созданию возвращались 27 раз в театре, кинематографе и литературе. На излете символизма в 1904 году Густав Майринк подхватывает идею бодимодификаций в своем мистическом и пугающем рассказе «Растения доктора Синдереллы». А в 1912 новые грани ужаса - уже психологического - в телесных трансформациях являет читателю Франц Кафка в повести «Превращение». С течением времени, пройдя эпохи романтизма, символизма и модернизма, тема бодимодификаций подошла к своему крайнему выражению в популярной культуре конца XX - начала XXI вв. в оригинальном жанре боди-хоррора.

К полному раскрытию темы боди-хоррора приближались постепенно, с середины XX века. Капля (1958), Голова-ластик (1977), Чужой (1979, 1986, 1992, 1997), Нечто (1982), Реаниматор (1985), Муха (1986), Восставший из ада (1987), Худеющий (1996), Вирус (1999), Слизняк (2006), Заноза (2008), Район №9 (2009), Человеческая многоножка (2009), Американская Мэри (2012), Бивень (2014) - это очень краткий список фильмов на тему боди-хоррора, демонтирующий эволюцию жанра и возможные его ответвления. Здесь и идея вселения в человеческий организм инородного существа-паразита, и идея перерождения человека в нечто невообразимое, и просто эксплуатация темы разрушения человеческой плоти всеми доступными методами и способами.

Боди-хоррор не ставит своей целью напугать потребителя ужасами разложения или чрезмерной натуралистичностью. Задача - вызвать не омерзение, а страх перед утратой контроля над собственным телом в результате насильственных или добровольных трансформаций, которым подвергает себя герой и или которым подвергают героя. Страх здесь зиждется на том, что в отличие от ситуации преследования маньяком или чудовищем, ты не можешь никуда убежать ужас внутри тебя, он с тобой. Ужас - это твое тело. Ужас - это ты сам.

Ряд критиков и исследователей указывают на фильм «Нечто» (1982, Дж. Карпентер), как на художественный текст, обозначивший переход к деконструкции тела и культивированию страха перед ним. Именно этот фильм порождает дискуссию вокруг самого термина - боди-хоррор или «биологический ужас». Собственно основная идея сводится к деформированию привычной телесности и утраты привычных же функций тела. Хотя, вместо одних функций вполне могут появиться иные. Подобного рода фильмы призваны не вызвать страх смерти как таковой - в этом нет ничего удивительного для фильмов подобного жанра (более того, другие жанры уже давно и успешно эксплуатируют этот страх) - а породить страх перед тем, что казалось бы не может стать твоим врагом. И в этом смысле боли-хоррор не то опередил, не то уловил тенденцию эпохи - тело может тебя предать и предает на каждом шагу. Примечательно, что Энн Джерсли, исследующая тематику зомби в художественных фильмах, указывает, что страх вызывает именно монструозное тело, а не монструозных характер [JERSLEV 1994: 18-33]. Разумеется, если речь о зомби, то какой уж тут характер! В этом и заключается основная идея, столь 
актуализировавшаяся в эпоху постгуманизма. Человек лишается своего пьедестала, как нечто бесконечно разумное и великое, творение господа, царь природы и т.д. На самом деле человек жалок и ничтожен, он даже свое тело контролировать не в состоянии.

В кинематографе традиционно одним из самых ярких представителей этого специфического жанра называют режиссера Дэвида Кроненберга. Не случайно его прозвали «певец мутаций». Еще в 1975 году в фильме «Судороги» режиссер вывел в качестве главного героя ученого, создающего паразита. Проблема в том, что этот паразит, попадая в человека, вызывает рост агрессии и сексуального желания. Так город захлестнула эпидемия насилия, обычные люди вдруг превратились в маньяков. Несмотря на очевидную кровавость произведения, интересен философский посыл: паразит снимает культурные барьеры, давая человеку возможность реализовать свои инстинкты и скрытые желания. Затем был фильм «Муха», где главный герой «сращивался» с насекомым не генном уровне. И, конечно же, фильм «Автокатастрофа»настоящий гимн членовредительству и эстетизация протезирования.

Одна из центральных тем боди-хоррора - это тема гибридов, получаемых в результате скрещивания представителей разных видов. Причем видов, принципиально несовместимых. В реальной жизни спаривание представителей разных видов ограничивается или исключается естественными репродуктивными барьерами. Но идея сама по себе настолько привлекательна, что писатели и режиссеры просто не могли обойти ее своим вниманием. К тому же, как мы помним, человечество озабочено проблемой усовершенствования своего тела, расширения возможностей за счет пластики, имплантов и всего того, о чем мы уже говорили. Художник будто бы предлагает нам задуматься над тем, что может получиться в результате этого самосовершенствования. Киборг, но не приводящий к гармонии, а несущий смерть.

Многие из произведений боди-хоррора - «Капля», «Чужой» - породили довольно крупные фэндомы. Поскольку жанр развивается, то вполне правомерно будет выделить и поджанры. В частности, это поджанр, определяемый темой утраты контроля над той или иной частью тела. Идея не нова, она родилась еще в годы господства экспрессионизма - в 1924 году на экраны выходит фильм «Руки Орлака» по роману Мориса Ренара. Главный герой, пианист, в результате несчастного случая лишается своих рук, что делает невозможным его карьеру. Потому он идет на трансплантацию и получает в результате сложной операции руки казненного убийцы. Разумеется, согласно законам жанра, эти руки желают убивать, а вот мозг хочет совсем иного. Герою повезло, повторная операция избавляет его от этого проклятья. Мы же получаем целое направление боди-хоррора, где чужие, полученные в результате операций глаза, руки, а то и вовсе сердце начинают вступать в конфликт с мозгом и толкать главного героя на путь зла.

Однако, можно не ограничиваться одним органом - почему бы просто не собрать новую личность из фрагментов тел других людей? Тема, очевидно, является идейной наследницей Мери Шелли. Так в 1988 году в свет выходит 
бестселлер Томаса Харриса «Молчание ягнят», экранизированный в 1991 Джонатаном Демми. Этот роман в полной мере реализовал идею создания новой идентичности за счет использования фрагментов плоти других людей. И вновь мы получаем целую серию подражаний.

Важно отметить, что многие темы современной культуры, и боди-хоррор здесь не исключение, унаследованы нами от эпохи модернизма XIX - первой полвины XX вв. Этот факт со всей очевидностью указывает на то, что страх перед предательством собственного тела напрямую связан с технологическим прогрессом. Не только Мери Шелли оказывается среди прародителей жанра. Так мы уже упоминали Франца Кафку, а в 1975 году выходит манга в жанре бодихоррор японского художника Хидэси Хино под названием «Мальчик-личинка». Связь с «Превращением» Ф.Кафки более чем очевидна. Закомплексованный школьник превращается в уродливую личину, от которой все отворачиваются. Другое дело, что у Кафки мы видим рассказ об одиночестве, о «незаметности» персонажа и его превращение в насекомое становится своеобразным апофеозом одиночества, в данном же случае речь идет об истории мести за все обиды.

Является ли боди-хоррор исключительно «развлекательным» жанром кино, литературы, компьютерных игр пр.? Нет, это не совсем так. Боди-хоррор способен выражать и социально значимые идеи, не связанные напрямую со страхом бодимодификаций. Так на полотнах художницы Сюзан Блак мы видим бесконечную галерею образов искалеченных мужчин и женщин, в большей степени женщин. Окровавленные, поломанные тела, соединенные с проводами и железной арматурой. Сюзан Блак протестует против мира мужчин, где женщина вечная жертва. Этот боди-хоррор наделен глубочайшим смыслом и содержит гуманистический посыл, несмотря на весь ужас того, что мы видим.

Очевидно, человек находит свое тело несовершенным. Художественный текст показывает наше стремление обрести качества, открывающие новые возможности - видеть в темноте, быстрее передвигаться, летать, обходиться без пищи, чаще прочего - минимизировать болевые ощущения и обрести бессмертие. Это то, к чему стремился человек эпохи архаики, надевая шкуру буйвола или леопарда. В иных случаях специфическая репрезентация бодимодификаций указывает и на стремление стать незаметным - превратиться в таракана, червя, иметь возможность спрятаться. В подобных примерах мы видим желание человека уйти от давления социальной среды, неспособность справиться с вызовами.

Человек осознает уязвимость и несовершенство своего тела. Также он понимает, что классический гуманизм обманывал его столетиями - он не царь природы, не венец творения. Человек - это агрессивное животное, по вине которого погибло 60\% видов других животных. Современный человек мечется между чувством вины за бесконечную череду войн и экоцид с одной стороны и всепоглощающим страхом перед миром. Не справляясь с вызовами современности, отдавая себе отчет в собственной ущербности, он всеми силами старается усовершенствовать себя посредством доступных бодимодификаций. Однако именно этот процесс вызывает у него новый приступ паники пред потенциальной утратой контроля над телом. Стремясь стать киборгом Донны 
Хуруэей, он, к собственному ужасу, осознает себя личинкой Хидэси Хино, несчастной и агрессивно-мстящей.

\section{Библиография}

ЛЕвинАс 2004: Левинас, Э., Трудная свобода. Очерки по иудаизму // Избранное: Трудная свобода. Москва: Российская политическая энциклопедия РОССПЭН.

ПодоРОГА 1995: Подорога, В.А. Феноменология тела. / DEJA VU алиби-не-алиби Режим доступа: http://ec-dejavu.ru/b/Body.html (25.07.2015), свободный. - Загл. с экрана - Яз. рус.

Рено 2002: Рено, А., Эра индивида. К истории субъективности. Санкт-Петербург: «Владимир Даль».

ХАЙДЕГГЕР 2002: Хайдеггер, М., Бытие и время, Санкт-Петербург: Наука.

ХАРАУЭЙ 2017: Харауэй, Д. Манифест киборгов: наука, технология и социалистический феминизм 1980-х. перевод с английского Гарадж А., Серия Minima, Москва: Маргинем Пресс.

JersLeV 1994: Jerslev, A., The Horror Film, the Body and the Youth Audience. // Young Nordic Journal of Youth Research, No. Vol 2, No 3. 18-33

Андрей ЧукуРОВ

Herzen State Pedagogical University

Saint-Petersburg, Russia achucurov@yandex.ru 